\title{
Simulation of Storm Surges in Bangladesh Using NWP Models
}

\author{
Quazi Aseer Faisal ${ }^{1}$, Towhida Rashid ${ }^{1}$, Muhammad Arif Hossain ${ }^{2}$, S. M. Quamrul Hassan ${ }^{2}$ and \\ Javed Meandad ${ }^{1}$
}

\author{
${ }^{1}$ Department of Meteorology, University of Dhaka, Dhaka 1000, Bangladesh \\ ${ }^{2}$ Bangladesh Meteorological Department, Agargaon, Dhaka 1207, Bangladesh \\ Manuscript received: 10 December 2020; accepted for publication: 18 February 2021
}

\begin{abstract}
Tropical cyclone causes enormous damage of property and life in the coastal regions of Bangladesh. Majority of the damage during tropical cyclone occurs because of storm surge. Bangladesh is vulnerable to storm surge flooding due to its complex geometry and location. The huge loss of property and life can be reduced by predicting storm surge during a tropical cyclone. So, an attempt has been made in this study to see the effectiveness of predicting storm surge by Meteorological Research Institute (MRI) storm surge model from Japan Meteorological Agency (JMA). In this study, MRI storm surge model is used to simulate storm surge of five cyclones cyclone Bulbul (November 2019), cyclone Fani (May 2019), cyclone Mora (May 2017), cyclone Roanu (May 2016) and cyclone Komen (July 2015) were simulated using MRI storm surge model to see the effectiveness of the model. The model was run for 48hours for two different data sets which are, European Centre for Medium-Range Weather Forecasts (ECMWF) data and Global Spectral Model (GSM) data. Simulated storm surge heights found from the model are compared with the reported surge height from Bangladesh Inland Water Transport Authority (BIWTA) and Bangladesh Meteorological Department (BMD). The model is able to simulate storm surge height, mean sea level pressure (MSLP) and wind data of all the selected cases. The time series graph developed using python comparing the simulated results of storm surge height data with observed data for the event cyclone Bulbul showed the simulated data of both NWP datasets were in line with the observed data. And comparison of the maximum storm surge height for all five events shows simulated data for both the data sets were close to the reported data and the difference was well within the margin of error. The results indicate MRI model as a useful tool for storm surge forecasting
\end{abstract}

Keywords: Storm Surge, Simulation, NWP, MRI Model, Bangladesh

\section{INTRODUCTION}

Bangladesh is one of the major disaster-prone countries in the world due to its geographical setting. It is a part of the Bengal Basin, one of the largest geosynclines in the world. The coastal region of Bangladesh is particularly vulnerable for cyclonic storm surge floods due to its location in the path of tropical cyclones, wide and shallow continental shelf and the funneling shape of the coast. This region is often affected by storm surge due to tropical cyclone as Bay of Bengal is located in the tropical part of the world. According to statistics of different researches, about $5 \%$ of the creation of global tropical cyclone develops over this region and Bangladesh faces approximately $40 \%$ of the damage of total storm surges in the world. Huge loss of life and damage of property to the coastal population is caused mainly by storm surges.

A lot of research on storm surge has been carried out throughout the years. The goal of many of these

Corresponding author: Quazi Aseer Faisal

Email: quaziaseer-2nd-2018510805@met.du.ac.bd

DOI: https://doi.org/10.3329/dujees.v9i1.54859 researches was to understand the process of storm surge disaster and if possible, to develop a system for prediction of storm surge disasters with a view to reduce the possible effect of storm surge disaster with proper management. To understand the process of occurrence of storm surge various models were introduced with the advancement in technology.

As-Salek (2001) observed negative surges in the Meghna estuary and its duration is about 4-6 h. These negative surges reduce maritime aquaculture connections and show extraordinary sensitivity to the astrological tides and to the circulation track of a cyclone in the region. Debsharma (2009) calculated time sequence of storm surges due to different cyclones and a $3 \mathrm{D}$ vision of the highest surges has also been completed through landfall. Higaki et al. (2009) have developed the outline of the storm surge prediction model at the Japan Meteorological Agency (JMA). They used the model to simulate storm surge that occurred in the coast of Japan. Mallik et al. (2015) used the Meteorological Research Institute (MRI) model to simulate the storm surge of Cyclone Viyaru as part of their research on the cyclone Viyaru. Paul et al. (2018) transformed the vertically integrated shallow water 
equations (SWEs) in Cartesian coordinates into ordinary differential equations (ODEs) of initial valued, which were then solved using the new RKARMS $(4,4)$ method to simulate storm surge. Ali et al. (2018) studied the storm surge event of cyclone Aila by simulating data from WRF model for cyclone Aila and used the output data to simulate the storm surge for cyclone Aila. Again in 2019 Ali et al. used the WRF model to simulate another cyclone in this case cyclone Roanu and then used the output data to simulate storm surge for the cyclone using MRI model to compare with the observed surge height data.

In this study, Meteorological Research Institute (MRI) storm surge model of Japan Meteorological Agency (JMA) is used to simulate five selected cases of tropical cyclone induced storm surges namely cyclone Bulbul (November 2019) cyclone Fani (May 2019) cyclone Mora (May 2017), cyclone Roanu (May 2016) and cyclone Komen (July 2015) with European Centre for Medium-Range Weather Forecasts (ECMWF) data and Global Spectral Model (GSM) data as input. The objective of the study is to compare the simulated storm surge events to understand the effectiveness of the MRI model and for more accurate storm surge forecasting.

\section{MODEL EXPERIMENTAL SET-UP, DATA USED AND METHODOLOGY}

\section{MRI Storm Surge Model}

Meteorological Research Institute (MRI) of JMA started working on developing the MRI storm surge model on the basis of two major factors for calculation of storm surge; inverse barometer effect and wind set up (Hasegawa et al., 2015). The model assumes tidal level as a constant parameter adding surges with a linear relation. Also visualization of tidal components at some grid point is also an option. However, astronomical tide and ocean wave conditions are not calculated in the model. The governing equations of the model are momentum equation and continuity equation (Higaki et al., 1998).

\section{Momentum equations}

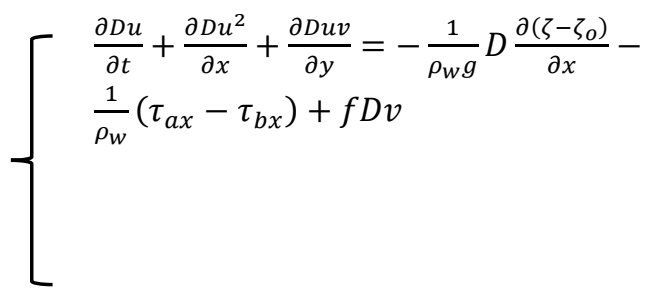

$$
\begin{aligned}
& \frac{\partial D v}{\partial t}+\frac{\partial D u v}{\partial x}+\frac{\partial D v^{2}}{\partial y}=-\frac{1}{\rho_{w} g} D \frac{\partial\left(\zeta-\zeta_{o}\right)}{\partial y}- \\
& \frac{1}{\rho_{w}}\left(\tau_{a y}-\tau_{b y}\right)+f D u
\end{aligned}
$$

\section{Continuity of mass}

$$
\frac{\partial \zeta}{\partial t}+\frac{\partial D u}{\partial x}+\frac{\partial D v}{\partial y}=0
$$

Where,

$\mathbf{x}=(x, y)$ indicates horizontal position,

$\mathbf{U}=(u, v)$ current velocity

$\zeta=$ height deviation

$\zeta_{0}=$ balance level with surface pressure

$\boldsymbol{\rho}_{w}=$ sea water density

$\boldsymbol{f}=$ Coriolis parameter

$g=$ gravitational acceleration

$\boldsymbol{\tau}_{\boldsymbol{a}}=\left(\tau_{a x}, \tau_{a y}\right)$ indicates stresses to waters, at surface by winds and at bottom by friction respectively.

The local heights of water are expressed by D, which is defined to the summation of the static level (water depth $H$ ) and deviation $\zeta$ :

$D(x, y, t)=H(x, y)+\zeta(x, y, t)$

\section{Model Experimental Setup}

Table 1 describes the functions of the model including profile, selected area and importantly tools that are used to visualize the output.

Table 1: Description of JMA MRI Storm Surge Model

\begin{tabular}{|l|l|}
\hline Model & $\begin{array}{l}\text { 2-dimentional ocean model, vertically } \\
\text { integrated }\end{array}$ \\
\hline Coordinate & Lat/Lon certesian grid (Arakawa C-Grid) \\
\hline Area & $8.5-23.5 \mathrm{~N}, 80-100 \mathrm{E}$ \\
\hline Grid resolution & $3.75 \mathrm{~km}$ x $3.75 \mathrm{~km}$ \\
\hline Forcing Data & GSMGPV $(25 \mathrm{~km})$ ECMWF $(25 \mathrm{~km})$ \\
\hline Pressure profile & Fujita \\
\hline $\begin{array}{l}\text { Visualization } \\
\text { Tools }\end{array}$ & GrADS \\
\hline Topographic data & Gebco $3 \mathrm{sec}$ resolution \\
\hline
\end{tabular}

\section{Data Used}

The reported maximum storm surge height data are collected for the selected 5 events of tropical cyclone namely Bulbul (November 2019), Cyclone Fani (May 2019), Cyclone Mora (May 2017), Cyclone Roanu (May 2016), Cyclone Komen (July 2015) from Bangladesh Meteorological Department (BMD. The hourly observed storm tide data for Bulbul during the 
period 05-12 November 2019 is also collected from Bangladesh Inland Water Transport Authority (BIWTA).

The European Centre for Medium-Range Weather Forecasts (ECMWF) data of 0.25 degree is used to simulate the 5 selected cases of tropical cyclonic namely Bulbul (2019), Fani (2019), Mora (2017), Roanu (2016) and Komen (2015). Three hourly Global Spectral Model (GSM) surface data for 48 hours of 0.25 degree resolution for these 5 selected cyclones are used as initial and lateral boundary conditions.

\section{Methodology}

All the selected storm surge cases are simulated for 48-hours using MRI model. The simulated output is visualized using Grid Analysis and Display System (GrADS). Three parameters are selected from the simulated output for visualization. They are height of the Storm Surge (in meter), mean Sea level Pressure (MSLP) (in hectopascal) and wind (Both speed and direction of zonal and meridional wind) (in meter/second)

The simulated storm surge height data of cyclone Bulbul (2019) is compared with the BIWTA observed data and develop a time series. Also a comparison graph of maximum storm surge height for all the events with reported data of Bangladesh Meteorological Department (BMD) is developed.

\section{RESULTS AND DISCUSSION}

\section{Cyclone Bulbul (2019)}

Storm surge simulation operations for cyclone Bulbul in MRI model begin simulation from $8^{\text {th }}$ November 00:00 UTC. The model remained operational for the next 48 hours finishing the simulation on $9^{\text {th }}$ November 23:59 UTC. The simulated results from the NWP-ECMWF data is shown in Figure 1 and the simulated results from the NWP-GSM data is shown in Figure 2. Height of the storm surge was relatively low during $8^{\text {th }}$ November but it gradually increased in $9^{\text {th }}$ November and between 04:00-08:00 UTC it increased from $0.6 \mathrm{~m}$ to $1.4 \mathrm{~m}$ for both the datasets. The visualization of MSLP indicates to about $988 \mathrm{hPa}$ at the time of cyclone, which is same for both datasets. The zonal and meridional component of the wind visualize the change in wind speed and direction for cyclone
Bulbul. Both the datasets show similar change in wind speed and direction.

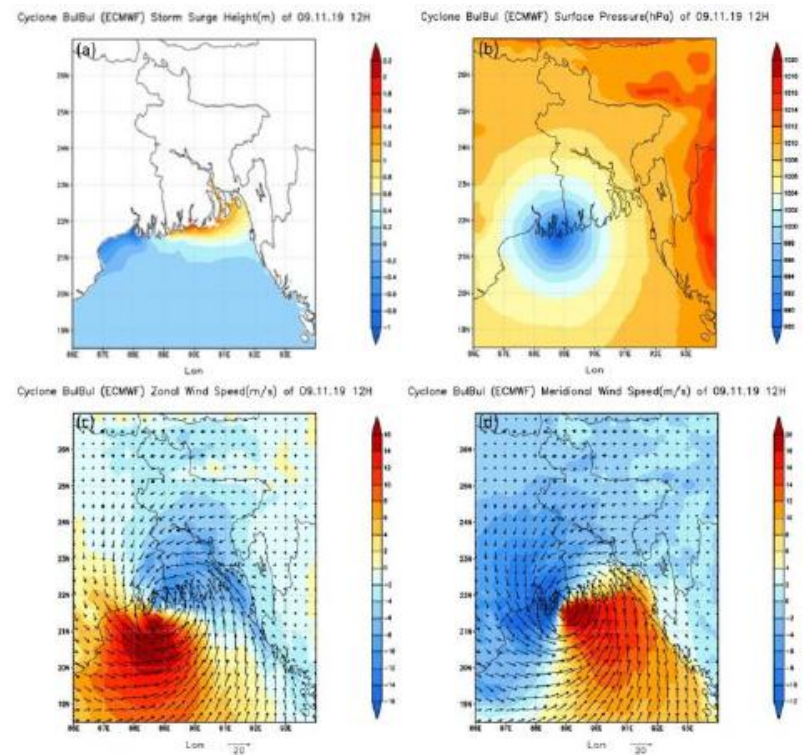

Figure 1: Simulated Storm Surge of Cyclone Bulbul (NWP-ECMWF data) (a) Storm Surge Height (m); (b) Mean Sea Level Pressure (hPa); (c) U-wind/zonal Wind $(\mathrm{m} / \mathrm{s}) ;(\mathrm{d}) \mathrm{V}$-wind/ meridional Wind $(\mathrm{m} / \mathrm{s})$

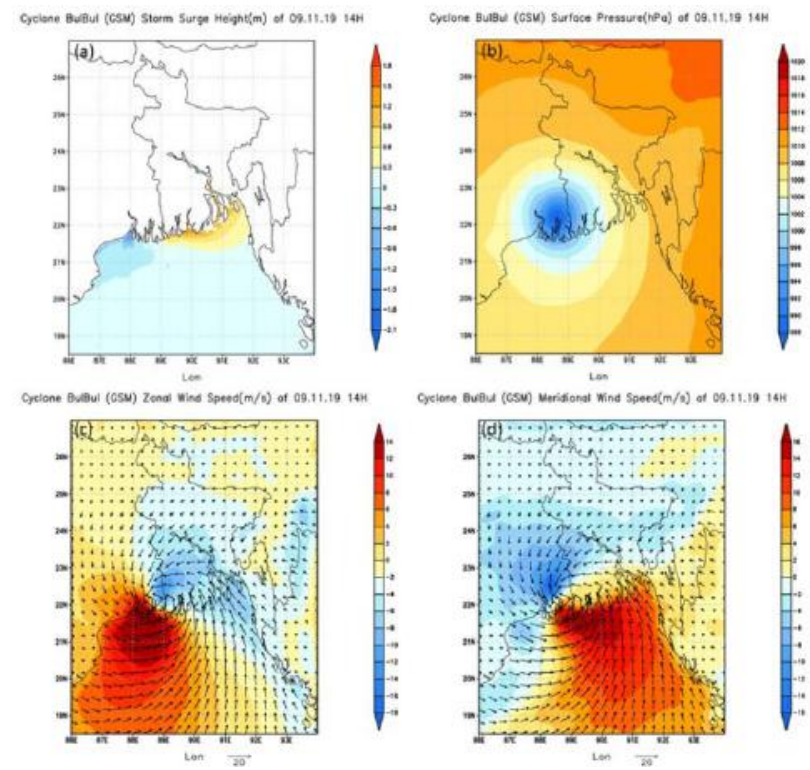

Figure 2: Simulated Storm Surge of Cyclone Bulbul (NWP-GSM data) (a) Storm Surge Height (m); (b) Mean Sea Level Pressure (hPa); (c) U-wind/zonal Wind (m/s); (d) $\mathrm{V}$-wind/ meridional Wind $(\mathrm{m} / \mathrm{s})$

\section{Cyclone Fani (2019)}

Storm surge simulation operations for cyclone Fani in MRI model begin simulation from $30^{\text {th }}$ April 00:00 UTC. The model remained operational for the next 48 hours finishing the simulation on $1^{\text {st }}$ May 23:59 UTC. The simulated results from the NWP- 
ECMWF data is shown in Figure 3 and the simulated results from the NWP-GSM data is shown in Figure 4. In case of cyclone Fani both datasets show low storm surge height. The MSLP is comparatively high at $1003 \mathrm{hPa}$. The change in wind speed and direction were minimum in case of zonal and meridional wind components however NWP-ECMWF data NWP-GSM data show different visualization.
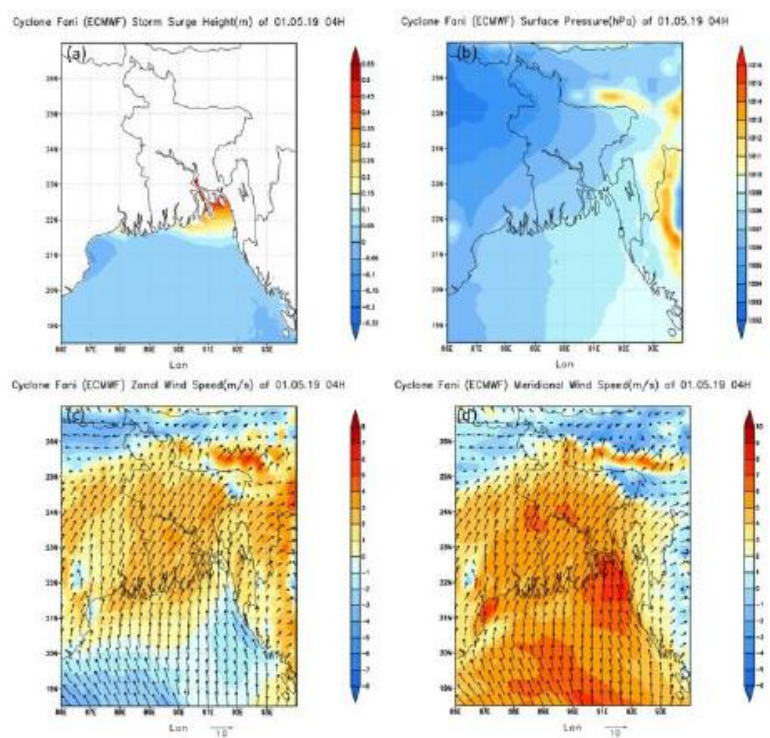

Figure 3: Simulated Storm Surge of Cyclone Fani (NWPECMWF data) (a) Storm Surge Height (m); (b) Mean Sea Level Pressure (hPa); (c) U-wind/zonal Wind (m/s); (d) Vwind/ meridional Wind $(\mathrm{m} / \mathrm{s})$
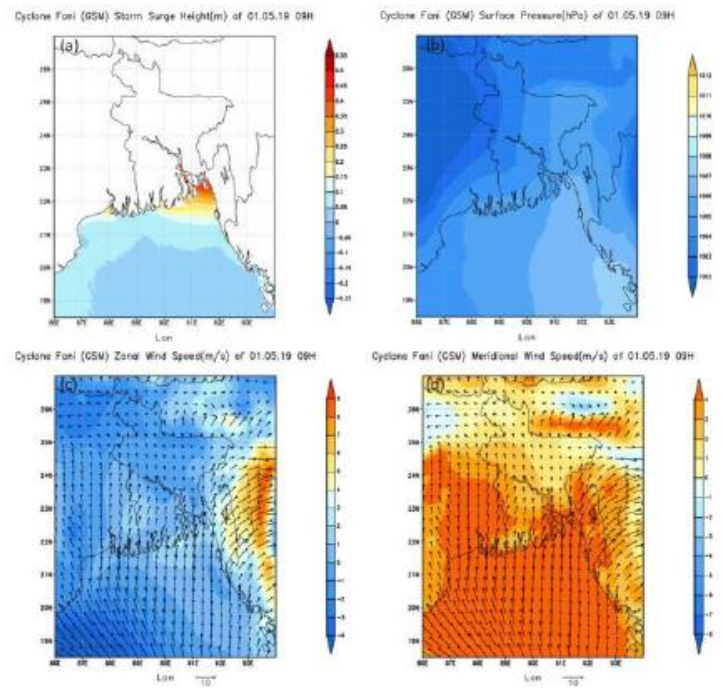

Figure 4: Simulated Storm Surge of Cyclone Fani (NWPGSM data) (a) Storm Surge Height (m); (b) Mean Sea Level Pressure (hPa); (c) U-wind/zonal Wind (m/s); (d) Vwind/ meridional Wind $(\mathrm{m} / \mathrm{s})$

\section{Cyclone Mora (2017)}

Storm surge simulation operations for cyclone Mora in MRI model begin simulation from $29^{\text {th }}$ May 00:00 UTC. The model remained operational for the next 48 hours finishing the simulation on $30^{\text {th }}$ May 23:59 UTC. The simulated results from the NWP-ECMWF data is shown in Figure 5 and the simulated results from the NWP-GSM data is shown in Figure 6. Both datasets show that the height of the storm surge increased to between $0.6-0.7 \mathrm{~m}$. The MSLP for both cases is 988 $\mathrm{hPa}$ which is an indication for the occurrence of a tropical cyclone. And further evidence of occurrence of cyclone is provided by the visualization of zonal and meridional wind components which shows the circular motion of the wind components.

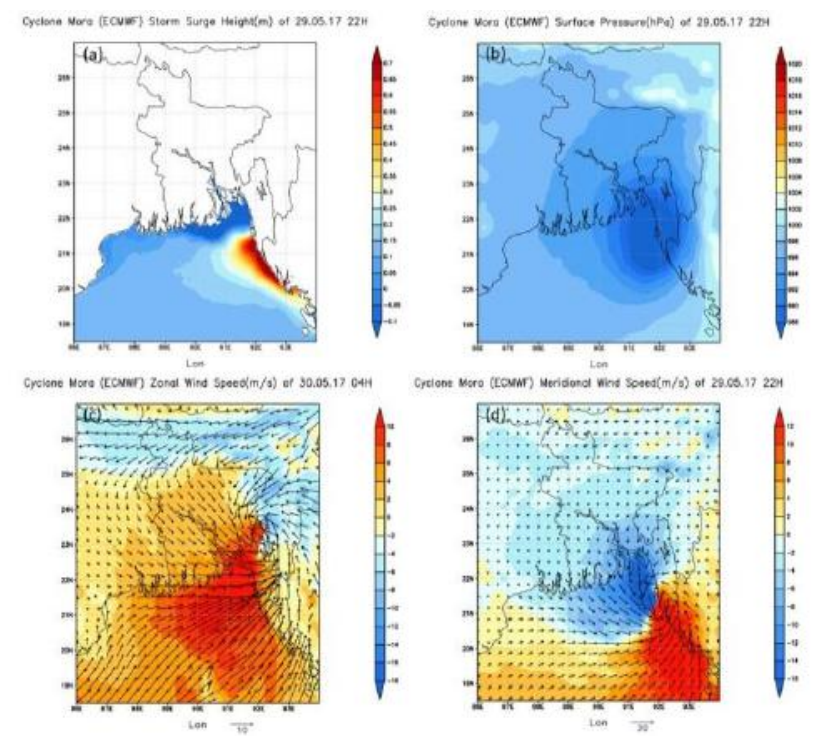

Figure 5: Simulated Storm Surge of Cyclone Mora (NWPECMWF data) (a) Storm Surge Height (m); (b) Mean Sea Level Pressure (hPa); (c) U-wind/zonal Wind (m/s); (d) Vwind/ meridional Wind $(\mathrm{m} / \mathrm{s})$

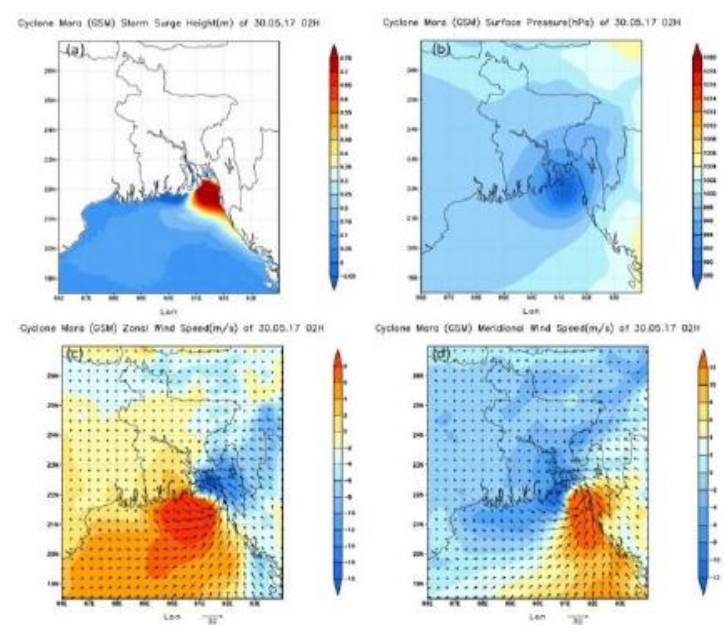


Figure 6: Simulated Storm Surge of Cyclone Mora (NWPGSM data) (a) Storm Surge Height (m); (b) Mean Sea Level Pressure (hPa); (c) U-wind/zonal Wind (m/s); (d) Vwind/ meridional Wind $(\mathrm{m} / \mathrm{s})$

\section{Cyclone Roanu (2016)}

Storm surge simulation operations for cyclone Roanu in MRI model begin simulation from $21^{\text {st }}$ May 00:00 UTC. The model remained operational for the next 48 hours finishing the simulation on $22^{\text {nd }}$ May 23:59 UTC. The simulated results from the NWP-ECMWF data is shown in Figure 7 and the simulated results from the NWP-GSM data is shown in Figure 8. In case of cyclone Roanu, the simulated storm surge height is very high increasing close to $1.8 \mathrm{~m}$ for NWP-ECMWF data. The MSLP for both datasets are $988 \mathrm{hPa}$ a common range in case of cyclone. The visualization of zonal and meridional wind components shows change in wind direction and circular motion of the wind components.

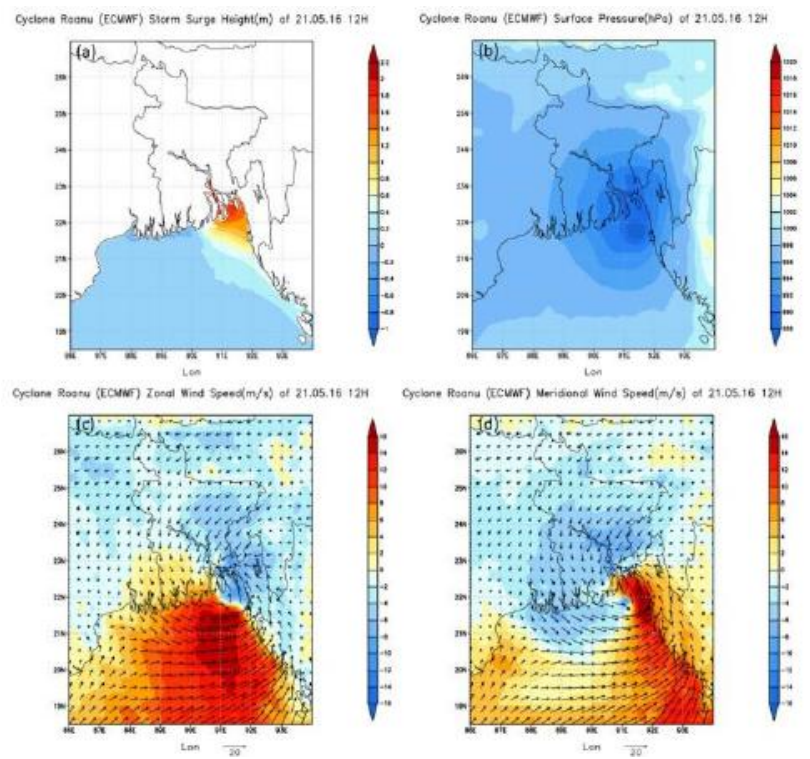

Figure 7: Simulated Storm Surge of Cyclone Roanu (NWP-ECMWF data) (a) Storm Surge Height (m); (b) Mean Sea Level Pressure (hPa); (c) U-wind/zonal Wind $(\mathrm{m} / \mathrm{s}) ;$ (d) V-wind/ meridional Wind $(\mathrm{m} / \mathrm{s})$

\section{Cyclone Komen (2015)}

Storm surge simulation operations of cyclone Komen in MRI model begin simulation from $29^{\text {th }}$ July 00:00 UTC. The model remained operational for the next 48 hours finishing the simulation on $30^{\text {th }}$ July 23:59 UTC. The simulated results from the NWPECMWF data is shown in Figure 9 and the simulated results from the NWP-GSM data is shown in Figure 10. The simulated height of the storm surge is in the range of $0.3 \mathrm{~m}$ to $1.5 \mathrm{~m}$ in terms both datasets. The
MSLP for NWP-GSM data is lower at $984 \mathrm{hPa}$ compared to NWP-ECMWF data. Also visualization of zonal and meridional wind components shows distinct circular motion of the wind components.
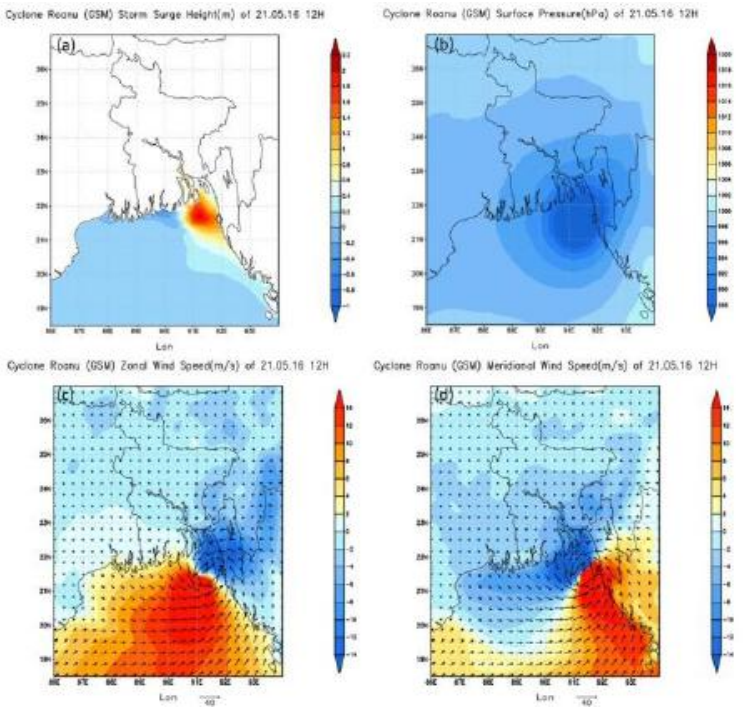

Figure 8: Simulated Storm Surge of Cyclone Roanu (NWP-GSm data) (a) Storm Surge Height (m); (b) Mean Sea Level Pressure (hPa); (c) U-wind/zonal Wind (m/s); (d) $\mathrm{V}$-wind/ meridional Wind $(\mathrm{m} / \mathrm{s})$

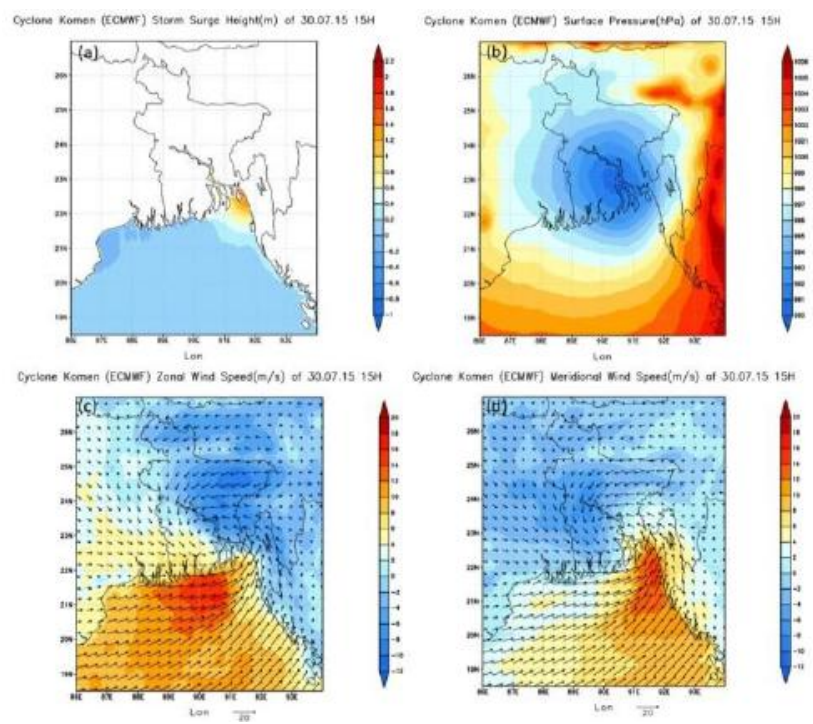

Figure 9: Simulated Storm Surge of Cyclone Komen (NWP-ECMWF data) (a) Storm Surge Height (m); (b) Mean Sea Level Pressure (hPa); (c) U-wind/zonal Wind $(\mathrm{m} / \mathrm{s})$; (d) V-wind/ meridional Wind $(\mathrm{m} / \mathrm{s})$

\section{Comparison of Simulation}

Simulated results of MSLP along with wind speed of zonal and meridional components of wind from both the NWP-ECMWF and NWP-GSM data for cyclone Bulbul were compared and using the data several time 
series graphs were developed. Figure 11 shows the comparison of mean sea level pressure (MSLP) between NWP-ECMWF and NWP-GSM datasets for a specific location. The figure shows that for the selected location the simulated MSLP of NWP-ECMWF data is lower at close to $1000 \mathrm{hPa}$ in comparison to NWPGSM data which is close to $1004 \mathrm{hPa}$.

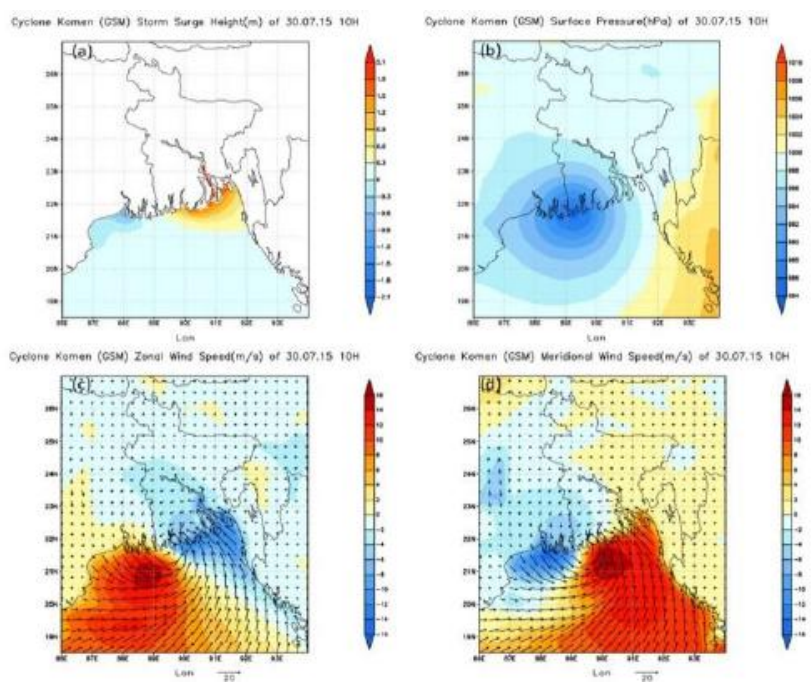

Figure 10: Simulated Storm Surge of Cyclone Komen (NWP-GSM data) (a) Storm Surge Height (m); (b) Mean Sea Level Pressure (hPa); (c) U-wind/zonal Wind (m/s); (d) V-wind/ meridional Wind ( $\mathrm{m} / \mathrm{s}$ )

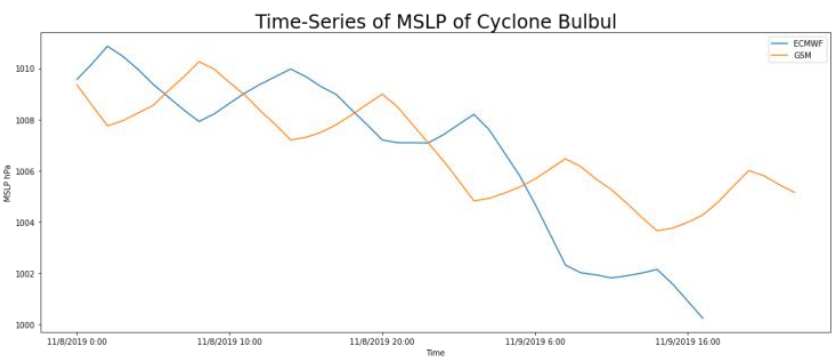

Figure 11: Comparative Time Series Graph for Mean Sea Level Pressure of Cyclone Bulbul Using Python

Figure 12 shows the comparison of wind speed of the zonal component of wind between NWP-ECMWF and NWP-GSM datasets for a specific location. Both datasets show similar change in wind speed however NWP-GSM data simulated higher wind speed at around $10 \mathrm{~m} / \mathrm{s}$ while NWP-ECMWF data simulated lower wind speed of $5 \mathrm{~m} / \mathrm{s}$.

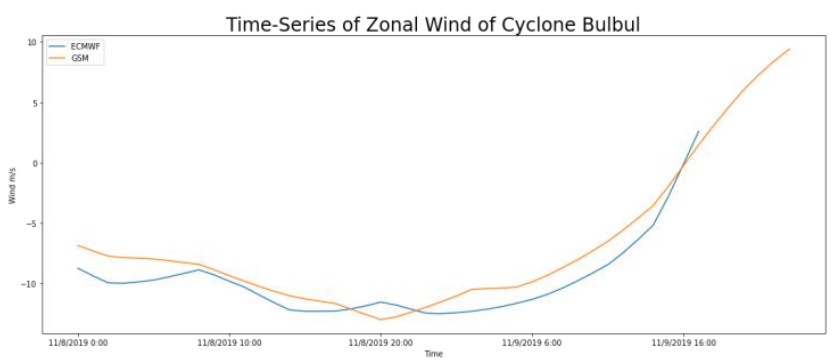

Figure 12: Comparative Time Series Graph for Zonal wind/U-wind of Cyclone Bulbul Using Python

Figure 13 shows the comparison of wind speed of meridional component of wind between NWPECMWF and NWP-GSM datasets for a specific location. The comparison shows a relatively higher wind speed for NWP-ECMWF data with a highest peak of $17.5 \mathrm{~m} / \mathrm{s}$ compared to NWP-GSM data which peaked at $15 \mathrm{~m} / \mathrm{s}$.

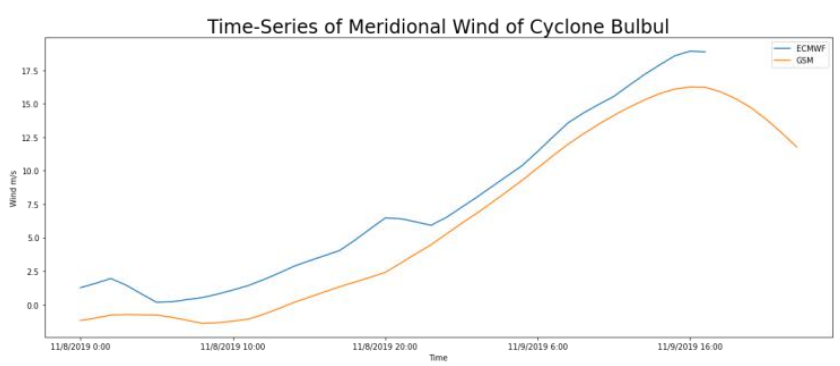

Figure 13: Comparative Time Series Graph for Meridional Wind/V-wind of Cyclone Bulbul Using Python

\section{COMPARISON WITH OBSERVED STORM SURGE HEIGHT}

\section{Comparison with BIWTA data for Cyclone Bulbul (2019)}

Figure 14 shows the time series graph of observed values and simulated values for storm surge height of cyclone Bulbul. The observed data was collected from Bangladesh Inland Water Transport Authority (BIWTA). BIWTA measured the height using datum points with mean sea level as the base. The simulated values come from NWP-ECMWF data and NWPGSM data. The Figure 14 shows that the observed values has more of a sinusoidal curve due to high tide and low tide while the simulated values are straighter lines as the model doesn't consider astronomical tide value. From the figure it is apparent that the simulated storm surge height of NWP-ECMWF data is closer to the peak of the observed data. 


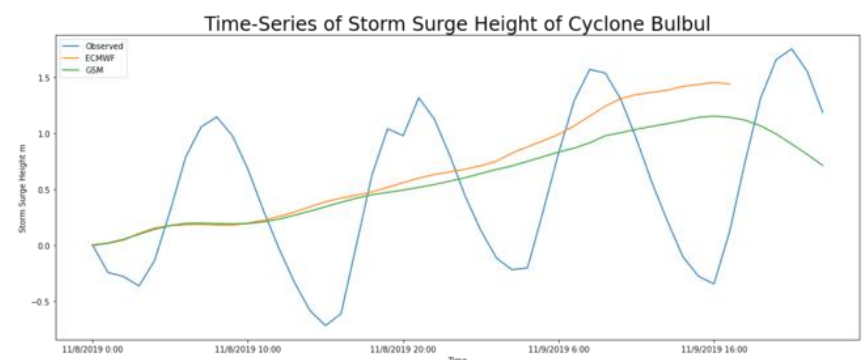

Figure 14: Comparative Time Series Graph of Observed and Simulated Data for Storm Surge Height of Cyclone Bulbul Using Python

\section{Comparison with BMD data}

Table 2 includes the reported maximum storm surge height data and the simulated maximum storm surge height data of both the NWP-ECMWF and NWP-GSM simulation of all five selected events. The reported storm surge height data was collected from Bangladesh Meteorological Department (BMD). BMD collected the reported maximum storm surge height data from the local newspaper. Figure 15 shows that comparison graph of maximum surge height. From the graph and the table it can be observed that for cyclone Bulbul NWP-ECMWF simulation slightly underestimates by $0.13 \mathrm{~m}$ than the reported data and NWP-GSM simulation is less by $0.63 \mathrm{~m}$ than reported data which could be due to model's limitation. For cyclone Fani both NWP-ECMWF and NWP-GSM simulation are less by $1.0 \mathrm{~m}$ and $1.05 \mathrm{~m}$ respectively than the reported data which could be due to model's limitation. For cyclone Mora NWP-ECMWF and NWP-GSM simulation underestimates by $0.40 \mathrm{~m}$ and $0.30 \mathrm{~m}$ respectively than the reported data which could be due to model's limitation. For cyclone Roanu NWP-ECMWF simulation slightly underestimates by $0.20 \mathrm{~m}$ than reported data and NWP-GSM simulation is less by $.90 \mathrm{~m}$ than reported data which could be due to model's limitation. For cyclone Komen NWPECMWF simulation slightly overestimates by $0.10 \mathrm{~m}$ than the reported data and NWP-GSM simulation overestimates by $0.30 \mathrm{~m}$ than reported data which could be due to model's limitation. Overall the results from NWP-ECMWF simulation was more accurate compared to NWP-GSM simulation.

Table 2: Comparison of Maximum Surge Height Between Simulated Data and Reported Data

\begin{tabular}{|c|c|c|c|}
\hline \multirow[b]{3}{*}{ Event } & \multicolumn{3}{|c|}{ Maximum Surge Height (m) } \\
\hline & & & \\
\hline & $\begin{array}{c}\text { NWP-ECMWF } \\
\text { data }\end{array}$ & $\begin{array}{c}\text { NWP-GSM } \\
\text { data }\end{array}$ & $\begin{array}{c}\text { Reported } \\
\text { data }\end{array}$ \\
\hline
\end{tabular}

\begin{tabular}{|l|c|c|c|}
\hline $\begin{array}{l}\text { Cyclone } \\
\text { Bulbul }\end{array}$ & 2.00 & 1.50 & 2.13 \\
\hline $\begin{array}{l}\text { Cyclone } \\
\text { Fani }\end{array}$ & 0.50 & 0.45 & 1.50 \\
\hline $\begin{array}{l}\text { Cyclone } \\
\text { Mora }\end{array}$ & 0.60 & 0.70 & 1.00 \\
\hline $\begin{array}{l}\text { Cyclone } \\
\text { Roanu }\end{array}$ & 1.80 & 1.10 & 2.00 \\
\hline $\begin{array}{l}\text { Cyclone } \\
\text { Komen }\end{array}$ & 1.60 & 1.80 & 1.50 \\
\hline
\end{tabular}

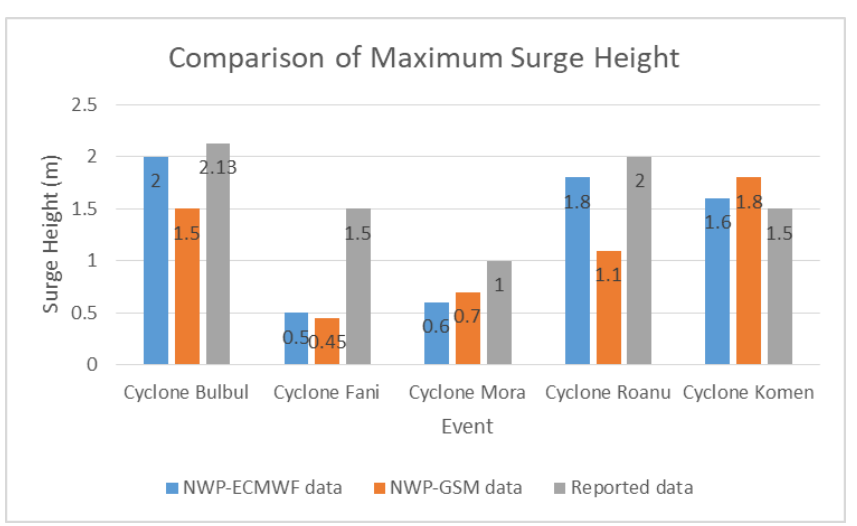

Figure 15: Comparative Graph of Reported and Simulated Data for Maximum Storm Surge Height

\section{Root Mean Square Error Calculation}

The Root Mean Square Error (RMSE) of both the datasets were calculated. Simulated value of maximum storm surge height of both datasets for all five selected events were taken and using the reported maximum storm surge height collected from BMD (which BMD collected from local newspaper) the RMSE was calculated. Table 3 shows the value of RMSE for both the datasets.

Table 3: RMSE of Simulated Results for Reported Maximum Storm Surge Height

\begin{tabular}{|c|c|}
\hline NWP Model Data & $\begin{array}{c}\text { RMSE (Root Mean Square } \\
\text { Error) }\end{array}$ \\
\hline NWP-ECMWF & 0.495 \\
\hline NWP-GSM & 0.705 \\
\hline
\end{tabular}

From the Table 3 it can be understood that RMSE value of NWP-ECMWF model data is lower in comparison to the RMSE value of NWP-GSM model data. This signifies that MRI storm surge model was able to simulate storm surge height of the selected events more accurately using the NWP-ECMWF model data as input. 


\section{CONCLUSION}

On the basis of the present study, the following conclusion can be drawn:

The study shows that the MRI Storm Surge model was able to simulate storm surge height, mean sea level pressure and wind component of all the selected storm surge events for both the datasets. All the simulations were in an hourly basis with a timeframe of 48 hours. It was possible to simulate and visualize storm surge height, mean sea level pressure, and wind component all three parameters in an hourly basis of all five selected events for the two datasets using GrADS visualization tool.

The time series graph comparing the simulated results and observed data of storm surge height for cyclone Bulbul shows that the simulated data of both NWP datasets are very similar to the observed data. And comparison of the maximum storm surge height for all five events shows that simulated data for both the data sets are close to the reported data and the difference was well within the margin of error.

The study shows that the MRI model is capable of simulating storm surge events that occur in the coastal region of Bangladesh. However currently there are no surge gauges installed along the coast of Bangladesh which hinders the availability of real time and dependable observation data. Installation of surge gauges will provide the data necessary for proper authentication of the model. This will further improve the accuracy of the model for forecasting storm surge events.

\section{REFERENCES}

Ali, M., Imran, A., Syed, I., Islam, J., and Mallik, M. (2018). A Comparative Study of Storm Surge Phenomenon Associated with the Tropical Cyclone
Aila over the Bay of Bengal Using NWP Models. Journel of Engineering Science, 09(02):33-40.

Ali, M., Saifullah, M., Imran, A., Syed, I., and Mallik, M. A. K. (2019). Studying the Intensity and Storm Surge Phenomena of Tropical Cyclone Roanu (2016) over the Bay of Bengal Using NWP Model. Journal of Scientific Research, 12(1):55-68.

As-Salek, J. A., and Takashi Y. (2001). Tide-Surge Interaction in the Meghna Estuary: Most Severe Conditions. Journal of Physical Oceanography, 31(10):3059-72.

Debsarma, S. K., (2009). Simulations of Storm Surges in the Bay of Bengal. Marine Geodesy 32(2):178-98.

Hasegawa, H., Kohno, N., and Hayashibara, H., (2015). JMA's storm surge prediction for the WMO storm surge Watch scheme (SSWS). Office of Marine prediction; Japan Meteorological Agency.

Hasegawa, H., Kohno N., and Itoh M., (2015). Development of storm surge model in Japan Meteorological Agency. Office of Marine prediction, JMA.

Higaki, M., Hironori, H., and Futoshi N. (1998). Outline of the Storm Surge Prediction Model at the Japan Meteorological Agency. 25-38.

Higaki, M., Hayashibara, H. H., and Nozaki, F. (2009). Outline of the Storm Surge Prediction Model at the Japan Meteorological Agency. Tech. rep., Office of Marine Prediction, Japan Meteorological Agency, RSMC Tokyo-Typhoon Center Technical Review, Tokyo, 924.

Mallik, M. A. K., Ahsan, M. N., and Chowdhury, M. A. M., (2015). Simulation of Track and Landfall of Tropical Cyclone Viyaru and Its Associated Strom Surges Using NWP Models. American Journal of Marine Science, 3(1):11-21. doi: 10.12691/marine-3-2-1.

Paul, G.C., Senthilkumar, S. and Pria, R. (2018). Storm Surge Simulation along the Meghna Estuarine Area: An Alternative Approach. Acta Oceanol. Sin. 37: 4049 (2018). https://doi.org/10.1007/s13131-018-11579. 